\title{
UK moves ahead on the xenotransplantation issue
}

The UK Secretary of Health issued new guidelines last month aimed at tightening regulations for xenotransplantation. The measures endorse the central role of the UK Xenotransplantation Interim Regulatory Authority (UKXIRA)-a temporary panel set up last year to address the issue of cross-species organ transplantsand declare the government's intention to work toward the establishment of a statutory body to oversee the technique. As in the US, all talk of a moratorium on xenotransplantation (Nature M ed., 4; 141, 1998) seems to have disappeared.

The guidelines are similar to those being adopted in the US and Spain (Nature M ed., 4; 876, 1998) and call for post-transplant patient surveillance, preclusion of great apes as donor animals and strict control over the production and welfare of porcine donors. For now, UKXIRA, with the support of expert assessors, will advise ministers on individual applications for human trials, although to-date none have been made, and on developments in efficacy and safety research.

In keeping with this latter aim, a closed workshop was held in London a week after the new guidelines were issued, to discuss a key safety issue - the potential of pig endogenous retroviruses (PERVs) to transfer to human recipients of pig organs. The decision to hold a closed meeting contrasts with recent government efforts to broaden the debate on new medical technologies through open discussion (Nature Med., 4; 875, 1998), and seems to be based partly on an odd pre sumption that the general public would not be interested in hearing the detailed scientific evidence.

Although UKXIRA will issue a report of its findings later in the year, those in attendance were unable to comment directly on the points raised. Nevertheless, coverage in the lay media of two of the studies presented, reporting no detection of PERVs in 35 patients who received either porcine islet cells or embryonic neurons (New Scientist, 159; 4, 1998), has stimulated a flurry of reports that pig organ transplants will be safe.

Imutran, a UK xenotransplantation company and a subsidiary of the pharmaceutical giant Novartis, issued a statement describing these results as "encouraging" but would not comment on data from a much larger study it is undertaking of 160 patients who have received pig tissue over the past 10 years. This study will be published before the end of the year.

These positive reports are believed to have been tempered by evidence from academic groups at the UKXIRA meeting. Robin Weiss of the Institute of Cancer

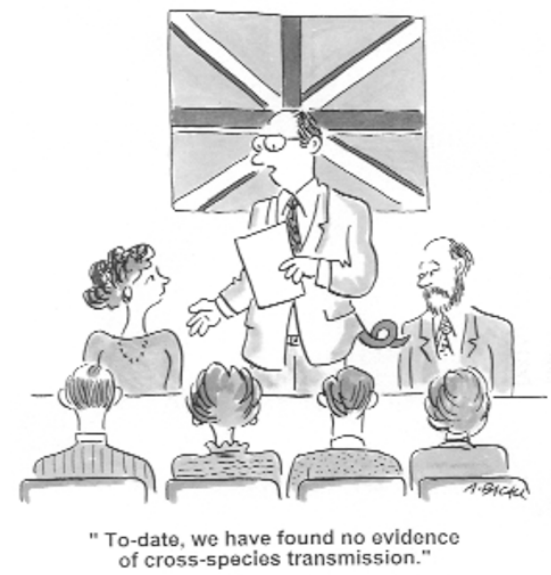

Research in London, whose group has studied three PERVs that selectively infect certain human cell types in culture (Nature Med., 3; 282, 1998) told Nature Medicine, "it is difficult to evaluate how infectious [PERVs] are for humans in the transplant setting." Weiss concedes that if the viruses were highly infectious, "we would be hearing the alarm bells by now from the handful of people who have been exposed that have been analyzed."
But he added the caveat, "you could draw the conclusion that since blood is the only sampleyou can directly get a hold of, it might be the wrong place to look. It depends if you are an optimist or pessimist." In a written response to Weiss' concern, Imutran stated, "Other tissues are included in some of [our] studies and it is the general scientific consensus that blood is the best means of screening."

Speaking separately on the new guidelines, Weiss lamented that after early leadership by the British authorities in establishing appropriate regulatory measures, the UK has fallen behind the US Food and Drug Administration in gathering and evaluating scientific evidence.

$\mathrm{He}$ also believes that initial concerns about zoonosis-a particular British sensitivity after the BSE scandal-have not engendered a sense of urgency in scrutinizing the available scientific evidence. He sees the prevailing attitude as an embrace of the new technology, a view confirmed by UKXIRA panel member Janet Dewdney: "We would set ourselves firmly against a moratorium on xenotransplantation because we need to move forward...taking on board the science as it develops. The fact that there are a lot of unknowns would certainly not make me feel it was appropriate to have a moratorium."

\section{Rebecca Currie, Edinburgh}

\section{European body to oversee tissue banks}

A European ethics group will meet in Turku, Finland, on September 10th-12th to finalize details for the establishment of a European Union hygiene security body that will test and evaluate human tissue to be used in transplantation for potential infectious diseases. The group first proposed the tissue hygiene body, which will examine tissue such as bone, skin, cornea, heart valves, pericardium and umbilical cord for pathogens that cause HIV, viral hepatitis and syphilis, in June this year.

The body will comprise transplant specialists, and Martí Manyalich, who has been elected to the committee, told $\mathrm{N}$ ature M edicine that although there is no test to detect the causative agent of Creutzfeldt-Jakob disease, the committee will give priority to the 'socio-medical' and family history of tissue donors to rule out the use of tissue that may have come from a CJD patient. For example, an individual with a personal history of a dementia would be excluded as a potential donor.

The idea of creating a tissue bank committee arose after the ethics group realized that, unlike organs and blood products, there is a regulatory gap on tissue bank material. The committee is expected to be organized by the end of the year if discussions in Finland are positive, and a proposal will be presented to the European Parliament to enforce the committees power. The ethics group, which says that no public or private institution or person may benefit from the committee's activities, anticipates the future creation of a shared European tissue bank registry to make a transcontinental exchange of human tissues possible.

Xavier Bosch, Barcelona 